\title{
The Ovarian Torsion Can We Use a Predictive Score
}

\section{Harou Karam, Billa Khalid, Boukhanni Lahcen, Aboulfalah Abderrahim, Asmouki Hamid, Soummani Abderraouf}

Obstetrics and Gynecology Department, Faculty of Medicine and Pharmacy, Mohammed VI University Hospital Center, Marrakech, Morocco

Email:dr.billa.khalid@gmail.com

How to cite this paper: Karam, H., Khalid, B., Lahcen, B., Abderrahim, A., Hamid, A. and Abderraouf, S. (2020) The Ovarian Torsion Can We Use a Predictive Score. Open Access Library Journal, 7: e6089. https://doi.org/10.4236/oalib.1106089

Received: January 19, 2020

Accepted: February 14, 2020

Published: February 17, 2020

Copyright $\odot 2020$ by author(s) and Open Access Library Inc.

This work is licensed under the Creative Commons Attribution International License (CC BY 4.0).

http://creativecommons.org/licenses/by/4.0/

\begin{abstract}
Adnexal torsion is difficult to diagnose and requires immediate surgery. Early diagnosis is necessary to preserve the function of the ovaries and tubes and prevent severe morbidity. The aim of this study is to evaluate the interest of the predictive score for assisting in the pre-operative diagnosis of adnexal torsion in women with acute pelvic pain.
\end{abstract}

\section{Subject Areas}

Surgery \& Surgical Specialties

\section{Keywords}

Adnexal Torsion, Pelvic Pain, Predictive Score

\section{Introduction}

Acute pelvic pain is the leading reason for emergency visits to gynecology departments [1]. Ovarian torsion accounts for up to $2.7 \%$ of all cases of acute abdominal pain. The symptoms of ovarian torsion are highly variable, leading to a potential delay in diagnosis with lifelong sequela for fertility [2].

Failure to establish the diagnosis early may lead to thrombophlebitis and peritonitis, which in turn may cause death. Conversely, laparoscopy may be performed unnecessarily in an effort to avoid missing an adnexal torsion [1].

Diagnosis usually relies on a combination of detailed clinical history and ultrasound findings, with a high index of suspicion for torsion. Attempts have been made to create scoring systems for the prediction of torsion, using clinical history and imaging findings. A recently published scoring system identified five criteria that were independently associated with adnexal torsion (Table 1) and 
Table 1. Predictive score for ovary torsion [1].

\begin{tabular}{cc}
\hline Criteria & Score points \\
\hline Spontaneous unilateral abdominal or lumbar pain & 15 \\
Pain duration $<\mathbf{8 ~ h}$ & 20 \\
Vomiting & 20 \\
Absence of leucorrhoea/metrorrhagia & 25 \\
Ovarian cyst $>\mathbf{5} \mathrm{cm}$ by ultrasound & 25 \\
\hline
\end{tabular}

allowed cases to be placed into low-risk (score value $\leq 40$ ) and high-risk (score value $>60$ ) groups [1].

The aim of this study is to evaluate this predictive score for the diagnosis of adnexal torsion in patients seen for acute pelvic pain, based on the medical history, clinical and ultrasound findings.

\section{Materials and Methods}

A retrospective review was performed with all cases of suspected and confirmed ovarian torsion recorded between January 2016 to December 2019 at our hospital.

Patients were identified using two search methods: the medical record database and the radiology database (ultrasound performed for patients with suspected ovary torsion). Ovary torsion was surgically confirmed.

Symptoms including the type, location and duration of pain, presence of nausea and vomiting, abdominal tenderness, leucorrhoea or vaginal bleeding at speculum examination, and adnexal masses at digital examination, ultrasound findings, pre-operative diagnosis, final diagnosis, and surgical management were recorded from the medical record. When data were missing, the relevant symptoms were considered absent.

On ultrasound, transverse and longitudinal images were obtained from the uterus and ovaries using a transabdominal and intravaginal approach. Vascular Doppler flows were recorded. Dimensions and volumes of uterus, ovaries, and any adnexal masses were calculated and recorded.

Thereafter, the patients were listed according to the presence or absence of the diagnostic criteria of the predictive score (Table 1 ) and a predictive value was established for each patient.

\section{Results}

Table 2 (annex) summarizes clinical features, ultrasound aspects, causes and surgical procedures.

The age of the patients ranged from 24 to 38 years with an average age of 28 years.

Time between onset of clinical signs and admission ranged from 2 hours to 3 days. 
Table 2. Summary of clinical features in our study. RLQ: right lower quadrant; LLQ: left lower quadrant.

\begin{tabular}{|c|c|c|c|c|c|c|c|c|c|}
\hline & age & $\begin{array}{l}\text { Clinical } \\
\text { features }\end{array}$ & $\begin{array}{l}\text { Duration } \\
\text { Of pain }\end{array}$ & $\begin{array}{c}\text { Pain } \\
\text { localization }\end{array}$ & ultrasound & $\begin{array}{l}\text { Doppler } \\
\text { (flow) }\end{array}$ & cause & surgery & $\begin{array}{l}\text { Score } \\
\text { points }\end{array}$ \\
\hline 1 & 24 & Pelvic pain & 5 hours & RLQ & Ovarian edema & + & No cause & $\begin{array}{l}\text { None } \\
\text { Spontaneous } \\
\text { detorsion }\end{array}$ & 60 \\
\hline 2 & 30 & Pelvic pain & 1 day & RLQ & $\begin{array}{c}\text { Peripheral echogenic } \\
\text { follicles } \\
\text { Ovarian cyst }=8 \mathrm{~cm}\end{array}$ & + & cyst & $\begin{array}{l}\text { detorsion and } \\
\text { Cystectomy }\end{array}$ & 65 \\
\hline 3 & 35 & $\begin{array}{l}\text { abdominal pain } \\
\text { vomiting } \\
\text { Fever } \\
22 \text { weeks of } \\
\text { pregnancy }\end{array}$ & 2 days & $\begin{array}{c}\text { Diffuse } \\
\text { abdominal } \\
\text { pain } \\
\text { Pelvic mass }\end{array}$ & $\begin{array}{l}\text { Right ovary edema } \\
\text { Abnormal ovarian } \\
\text { location (anterior to } \\
\text { the uterus) } \\
\text { Free fluid in Douglas } \\
\text { pouch }\end{array}$ & + & $\begin{array}{l}\text { Appendicular } \\
\text { peritonitis }\end{array}$ & $\begin{array}{c}\text { Appendectomy } \\
\text { detorsion Cystectomy }\end{array}$ & 60 \\
\hline 4 & 26 & $\begin{array}{l}\text { Pelvic pain } \\
\text { Nausea } \\
\text { vomiting } \\
\text { leucorrhoea }\end{array}$ & 12 hours & RLQ & Ovarian cyst $=4 \mathrm{~cm}$ & + & cyst & $\begin{array}{l}\text { detorsion } \\
\text { Cystectomy }\end{array}$ & 35 \\
\hline 5 & 24 & Pelvic pain & 1 day & LLQ & Enlarged ovary & - & No cause & detorsion None & 40 \\
\hline 6 & 30 & $\begin{array}{l}\text { Pelvic pain } \\
\text { vomiting }\end{array}$ & 8 hours & RLQ & $\begin{array}{c}\text { Ovarian edema } \\
\text { Peripheral echogenic } \\
\text { follicles }\end{array}$ & - & Not reported & detorsion None & 80 \\
\hline 7 & 38 & $\begin{array}{l}\text { Pelvic pain } \\
\text { Pelvic mass }\end{array}$ & 2 days & LLQ & Enlarged ovary & - & No cause & detorsion None & 40 \\
\hline 8 & 25 & $\begin{array}{l}\text { Pelvic pain } \\
\text { vomiting }\end{array}$ & 1 day & LLQ & Ovarian cyst $=6 \mathrm{~cm}$ & + & cyst & $\begin{array}{l}\text { detorsion } \\
\text { Cystectomy }\end{array}$ & 85 \\
\hline 9 & 33 & $\begin{array}{l}\text { Pelvic pain } \\
\text { Nausea } \\
\text { vomiting }\end{array}$ & 3 days & RLQ & $\begin{array}{c}\text { Ovarian edema } \\
\text { Heterogenic ovary } \\
\text { Ovarian cyst }=10 \mathrm{~cm}\end{array}$ & - & cyst & $\begin{array}{c}\text { detorsion } \\
\text { oophorectomy }\end{array}$ & 85 \\
\hline 10 & 24 & Pelvic pain & $\begin{array}{l}\text { Not re- } \\
\text { ported }\end{array}$ & RLQ & Normal ovary & + & cyst & $\begin{array}{l}\text { Detorsion } \\
\text { Cystectomy }\end{array}$ & 40 \\
\hline 11 & 31 & Pelvic pain & 2 hours & RLQ & $\begin{array}{c}\text { Ovarian cyst }=5 \mathrm{~cm} \\
\text { Ovarian edema }\end{array}$ & + & cyst & $\begin{array}{l}\text { Detorsion } \\
\text { Cystectomy }\end{array}$ & 85 \\
\hline 12 & 25 & Pelvic pain & 1 day & RLQ & Ovarian cyst $=6 \mathrm{~cm}$ & + & cyst & $\begin{array}{l}\text { Detorsion } \\
\text { cystectomy }\end{array}$ & 65 \\
\hline 13 & 24 & Pelvic pain & 8 hours & RLQ & $\begin{array}{c}\text { Ovarian edema } \\
\text { Ovarian cyst }=6 \mathrm{~cm}\end{array}$ & + & Hemorrhagic cyst & - & 85 \\
\hline 14 & 30 & $\begin{array}{l}\text { Pelvic pain } \\
\text { vomiting }\end{array}$ & 5 hours & RLQ & Ovarian edema & + & appendicitis & appendectomy & 80 \\
\hline 15 & 30 & $\begin{array}{l}\text { Pelvic pain } \\
\text { Vomitinig } \\
35 \text { weeks of } \\
\text { pregnancy }\end{array}$ & 7 hours & RLQ & Swollen appendage & + & $\begin{array}{l}\text { intestinal } \\
\text { constriction } \\
\text { on bridle }\end{array}$ & Intestinal release & 80 \\
\hline 16 & 28 & $\begin{array}{l}\text { Pelvic pain } \\
\text { metrorrhagia }\end{array}$ & 2 days & LLQ & Ovarian cyst $=8 \mathrm{~cm}$ & + & $\begin{array}{c}\text { Hemorrhagic } \\
\text { cyst }\end{array}$ & $\begin{array}{c}\text { Analgesic } \\
\text { Good evolution }\end{array}$ & 40 \\
\hline 17 & 29 & $\begin{array}{l}\text { Pelvic pain } \\
\text { leucorrhoea }\end{array}$ & 3 days & LLQ & Ovarian abscess & + & $\begin{array}{l}\text { Ovarian } \\
\text { abscess }\end{array}$ & $\begin{array}{l}\text { Abdominal wash } \\
\text { Abscess drainage }\end{array}$ & 15 \\
\hline
\end{tabular}

Clinical manifestations were dominated by localized abdominal pain at the torsion site. To this table were associated: vomiting (7 cases), fever in one case, pregnancy ( 2 cases) and metrorrhagia in one case. 
The clinical examination found a generalized abdominal defense in one case and a palpable pelvic mass in one case.

An abdominopelvian ultrasound in mode B and color Doppler was performed in all patients specifying the appearance and vascular flow of the ovary. Ultrasound showed a right ovarian cyst in 6 cases and a left ovarian cyst in 2 cases.

In nine cases the ovary was edematous and enlarged, heterogeneous in a case suggestive of ovarian necrosis, the follicles were located in the periphery in two cases. The ovary was normal in two cases:

Ultrasonography revealed an intraperitoneal effusion in one case.

The absence of color Doppler flow was noted in 4 cases.

Fifteen patients were treated by laparotomy, allowing the discovery of ovarian torsion (Figure 1(a)) on ovarian cyst in 8 cases, including one case of hemorrhagic necrosis, in 4 cases the ovary was swollen and edematous without visible mass.

Conservative ovarian treatment was performed in 11 patients with ovarian detorsion (Figure 1(b)) and cystectomy in 7 patients.

Unilateral adnexectomy was performed in one case because of ovarian necrosis (Figure 2).

Two appendectomies with peritoneal cavity washing in a case of appendiceal peritonitis and a case of appendicitis.

A case of abdominal washing and drainage of abscess.

The follow-up was simple in all patients except for an early abortion in the pregnant patient despite tocolytic treatment.

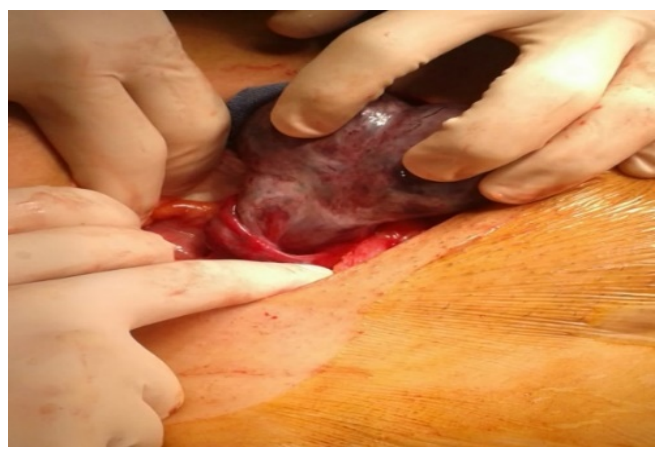

(a)

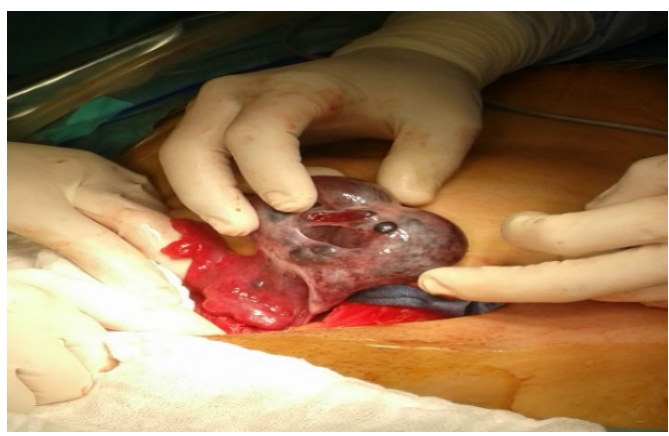

(b)

Figure 1. (a) Right ovary torsion; (b) Ovary detorsion. 


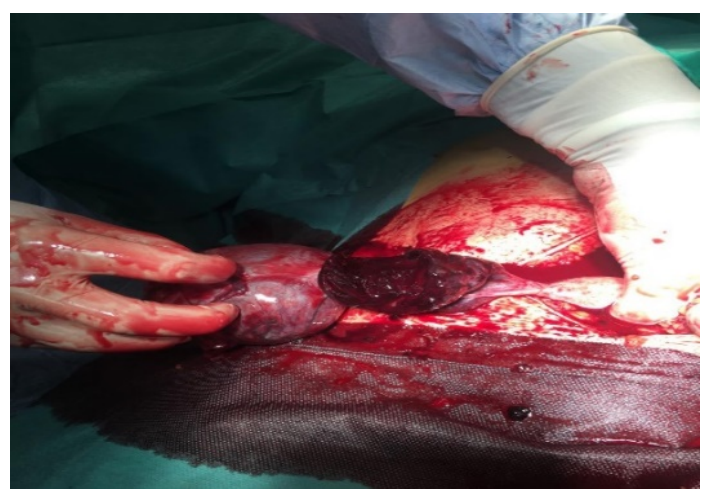

(a)

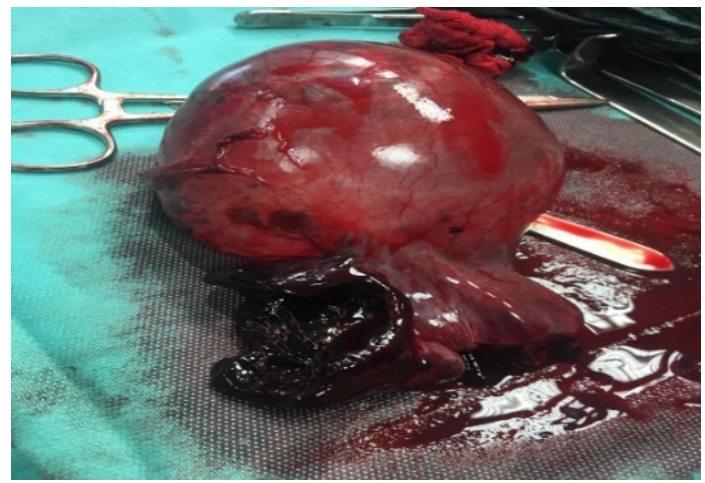

(b)

Figure 2. (a) Right ovary necrosis; (b) Ovary necrosis due to ovary torsion.

\section{Statistical Results}

For each patient in the retrospective cohort, the torsion score was calculated and correlated with the final diagnosis. The diagnostic performance characteristics and the probability of AT in each probability-level group are reported in Table 3.

In our study this score has a sensitivity of $66 \%$, a specificity of $40 \%$, a positive predictive value of $72 \%$ and a negative predictive value of $33 \%$.

\section{Discussion}

Ovarian torsion is defined as partial or complete rotation of the ovarian vascular pedicle causing obstruction to venousout flow and arterial inflow [3]. When fallopian tube also twists with the ovary, it is known as adnexal torsion [4].

Torsion of the ovary, tube or both is responsible for between $2.7 \%$ and $7.4 \%$ of all gynecological emergencies but is a common diagnostic challenge in the emergency setting [5]. It most commonly occurs in women of reproductive age (including during pregnancy) however, prepubertal girls and postmenopausal women can also be affected. Delay or misdiagnosis can result in the loss of the affected ovary and subsequent reduced reproductive capacity. However, diagnosis can be difficult, particularly in intermittent torsion and the differential diagnosis can include several other gynecological and surgical emergencies. Ovarian 
Table 3. The performance of the predictive score correlated with the final diagnosis.

\begin{tabular}{ccc}
\hline & Ovarian torsion & Non torsion \\
\hline High risk & 8 cases & 3 cases \\
Low risk & 4 cases & 2 cases \\
\hline
\end{tabular}

torsion is far less common than other causes of acute pelvic pain such as pelvic inflammatory disease (PID), ovarian cyst hemorrhage and appendicitis.

The clinical presentation of adnexal torsion, like other pathologies, is with acute onset of pelvic pain but can be non-specific, frequently presenting diagnostic difficulties. It was a common clinical sign in all of our patients.

Nausea and vomiting are also common presenting features, occurring in 85\% of cases of ovarian torsion [6], described in multiple studies as a common accompanying symptom [2], present in 7 out of 17 of our patients.

Similarly, a shorter duration of time from onset of the symptoms to presentation has also been reported [2]. In our study 6 cases had a duration of less than 8 hours between the onset of the pelvic pain and the consultation in the emergency department.

A low-grade pyrexia and sinus tachycardia may also be present.

The absence of leucorrhoea and metrorrhagia was significantly associated with adnexal torsion in our study probably reflects the occurrence of both symptoms in patients with other diagnoses, only 2 cases in our study presented leucorrhoea at the clinical examination.

Leukocytosis may be noted. Alternatively, patients can have a subacute presentation, with days or weeks of episodic pelvic pain [7].

It is key to take a detailed history of any woman presenting with acute pelvic pain when ovarian torsion is suspected.

\subsection{Ultrasound}

Data regarding cyst size and risk of torsion are conflicting, with some suggesting that torsion may be more likely in larger cysts $(>5 \mathrm{~cm}$ ) (Figure 3) [8]. Ovarian volume has been reported to be a common finding in ovary torsion [9].

Others suggest that cysts larger than $5 \mathrm{~cm}$ in size are less likely to undergo torsion than smaller ones. It has also been suggested that malignancies and endometriomas undergo torsion less frequently because of their association with pelvic adhesions [8]. An ovarian cyst $>5 \mathrm{~cm}$ was diagnosed in 7 patients.

The ultrasound appearance of torsion of a normal ovary (Figure 3) can be highly variable, representing the dynamic nature of the pathophysiological process.

There are three ultrasound features that are more specific and therefore more useful in diagnosis: the whirlpool sign of the pedicle, abnormal Doppler flows and the follicular ring sign [10].

It is therefore essential to be aware of the different possible ultrasound appearances and combine these with the clinical picture in order to make a swift 


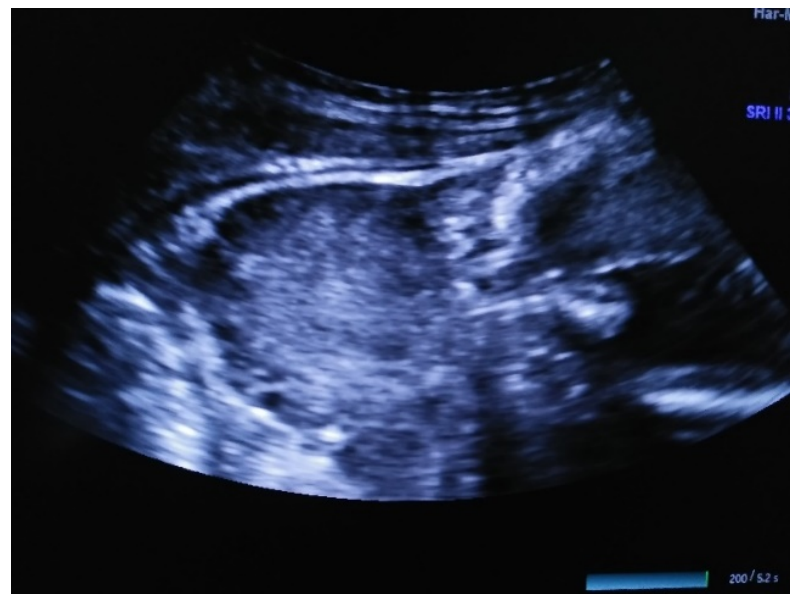

(a)

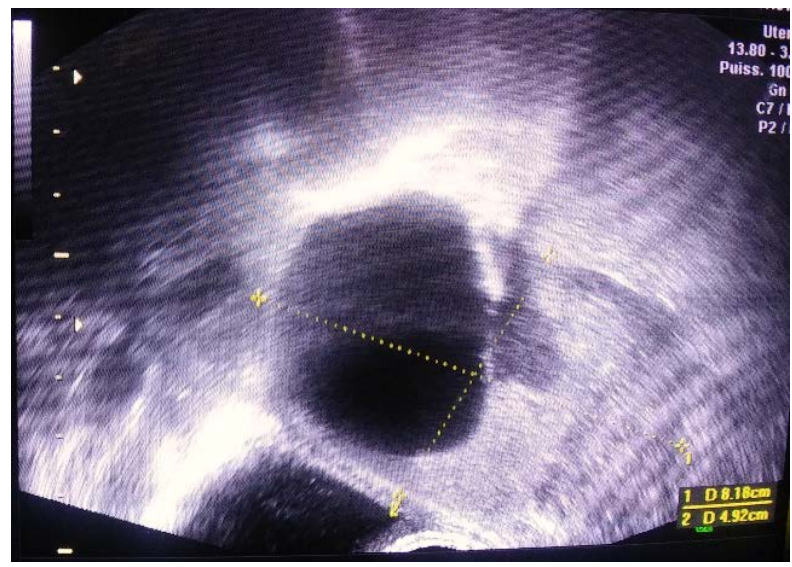

(b)

Figure 3. (a) Normal left ovary; (b) Ovarian cyst.

diagnosis of ovarian torsion. It is frequently described as unilateral ovarian enlargement and edema with peripherally arranged follicles (2 cases in our study).

The affected ovary may appear as a solid mass with hypo- and hyperechoic areas in keeping with hemorrhage and necrosis.

The pedicle that is twisted may be seen as a 'whirlpool' that is visible both in grey scale and on color Doppler and has been shown to increase the diagnostic sensitivity for torsion.

Of the above appearances, unilateral ovarian enlargement and edema appear to be the most consistent finding in the literature (10 cases).

If there is a simple cyst within the ovary, the cyst tends to become hemorrhagic as the ovary undergoes venous congestion, so the fluid within it becomes more echogenic. Normal ovarian tissue adjacent to the cyst also becomes edematous and the borders of the ovary less well defined. Abnormal Doppler signals in the ovarian vessels have been identified in up to $100 \%$ of cases of adnexal torsion; however, a complete absence of perfusion may be a relatively late event (4 cases), so the presence of flow within the ovary does not exclude the diagnosis of torsion. 
In any case of suspected ovarian torsion, comparison with the contralateral ovary will show a distinct difference in the appearances of the two ovaries. There is often hemorrhagic fluid in the pouch of Douglas but this is not invariable (1 case). Anechoic fluid in the pelvis may be a normal finding, so cannot be used as a marker of torsion.

\subsection{Other Imaging Techniques}

Computed tomography and magnetic resonance imaging (MRI) have been shown to be useful in the diagnosis of adnexal torsion and findings include enlargement of the ovarian stroma, ascites and uterine deviation to the affected side, with a good negative predictive value. These modalities are expensive however, are less readily available than ultrasound and rarely provide additional diagnostic information. MRI is more useful [11] in the second and third trimesters of pregnancy for diagnosing abdominal pain. We have not performed a complementary radiological assessment for our patients.

\subsection{Serum Markers}

The commonest and easiest marker to examine is C-reactive protein; the white cell count is also often measured and is raised in approximately $50 \%$ of women with adnexal torsion. Unfortunately, neither of these markers has been found to be useful in the diagnosis of torsion because of low sensitivity and specificity. Several other pro-inflammatory markers (such as interleukin- 6 and tumornecrosis factor- $\alpha$ ) have been assessed, but again, none have proved to have sufficient diagnostic accuracy to enter into routine use [12].

\subsection{Statistical Analysis}

Our results show that this score is neither sensitive nor specific in our study. However, although the current scoring system has not yet been put into an official protocol or clinical guideline [13], it may improve triage, evaluation, and management of young females who present to the emergency with lower abdominal pain. Although torsion often can be conservatively successfully managed with adnexal sparing, surgical management sometimes results in salpingo-oophorectomy. Increased accuracy and efficiency of the diagnosis could lead to less unnecessary surgical intervention and especially oophorectomy.

Efficient diagnosis of ovarian torsion is important in the management of ovarian torsion. Recognizing evidence of torsion on any imaging modality can mean the difference between prompt therapy and ovarian necrosis, including all associated risks of necrosis. In the appropriate clinical setting, torsion should be strongly considered in a diffusely enlarged ovary, even if vascular flow is identifiable on ultrasound [14].

Future studies are needed to prospectively test and validate this score, especially given the relatively small sample size used to create the composite score. Due to the relative rarity of this condition, a multi-center study would allow for 
a larger population and increased generalizability of this predictive model.

\section{Conclusions}

This easy-to-calculate score may prove useful for diagnosing adnexal torsion in patients with acute pelvic pain seen at general or gynecology emergency departments.

Since no considerable experience in gynecology or radiology is needed to assess the five score items, the torsion score may be suitable for routine use by any physician or resident as a non-invasive tool for separating patients having low versus high probabilities of adnexal torsion and for identifying patients who require emergency laparoscopy.

Prospective multicenter studies are needed to evaluate the diagnostic performance of the torsion score compared with standard clinical evaluation, in large numbers of patients.

\section{Conflict of Interest}

None declared.

Informed consent obtained from the patient to report the case.

\section{References}

[1] Huchon, C., Staraci, S. and Fauconnier, A. (2010) Adnexal Torsion: A Predictive Score for Pre-Operative Diagnosis. Human Reproduction, 25, 2276-2280. https://doi.org/10.1093/humrep/deq173

[2] King, A., Keswani, S., Biesiada, J., Breech, L., Crombleholme, T. and Huppert, J. (2014) The Utility of a Composite Index for the Evaluation of Ovarian Torsion. European Journal of Pediatric Surgery, 24, 136-140. https://doi.org/10.1055/s-0033-1343084

[3] Acimi, S. (2016) Acute Ovarian Torsion in Young Girls. Journal of Acute Disease, 5, 59-61. https://doi.org/10.1016/j.joad.2015.07.006

[4] Holbrook, J., Schneller, C., Lapping-Carr, G., Hageman, J.R. and Lo, A. (2015) A 3-Year-Old Female with Abdominal Pain, Vomiting, and an Abdominal Mass. Pediatric Annals, 44, e6-e9. https://doi.org/10.3928/00904481-20151226-08

[5] Damigos, E., Johns, J. and Ross, J. (2012) An Update on the Diagnosis and Management of Ovarian Torsion. The Obstetrician \& Gynaecologist, 14, 229-236. https://doi.org/10.1111/j.1744-4667.2012.00131.x

[6] Oelsner, G. and Shashar, D. (2006) Adnexal Torsion. Clinical Obstetrics and Gynecology, 49, 459-463. https://doi.org/10.1097/00003081-200609000-00006

[7] Sintim-Damoa, A., Majmudar, A.S., Cohen, H.L. and Parvey, L.S. (2017) Pediatric Ovarian Torsion: Spectrum of Imaging Findings. Radiographics, 37, 1892-1908. https://doi.org/10.1148/rg.2017170026

[8] Huchon, C. and Fauconnier, A. (2010) Adnexal Torsion: A Literature Review. The European Journal of Obstetrics \& Gynecology and Reproductive Biology, 150, 8-12. https://doi.org/10.1016/j.ejogrb.2010.02.006

[9] Servaes, S., Zurakowski, D., Laufer, M.R., Feins, N. and Chow, J.S. (2007) Sonographic Findings of Ovarian Torsion in Children. Pediatric Radiology, 37, 446-451. https://doi.org/10.1007/s00247-007-0429-x 
[10] Sibal, M. (2017) Ultrasound in Gynecology: An Atlas and Guide. Springer, Berlin, 413-428. https://doi.org/10.1007/978-981-10-2714-7 11

[11] Eskandar, O., Eckford, S. and Watkinson, T. (2010) Safety of Diagnostic Imaging in Pregnancy. Part 2: Magnetic Resonance Imaging, Ultrasound Scanning and Doppler Assessment. Obstetrics \& Gynecology, 12, 171-177.

https://doi.org/10.1576/toag.12.3.171.27599

[12] Zangene, M., Ashoori Barmchi, A., Rezaei, M. and Veisi, F. (2017) The Comparison between the Serum Level of Interleukin-6 in Women with Acute Ovarian Torsion and Other Causes of Lower Abdominal Pain. Journal of Obstetrics and Gynaecolo$g y, 37,223-227$. https://doi.org/10.1080/01443615.2016.1234435

[13] Schwartz, B.I., Huppert, J.S., Chen, C., Huang, B. and Reed, J.L. (2018) Creation of a Composite Score to Predict Adnexal Torsion in Children and Adolescents. Journal of Pediatric and Adolescent Gynecology, 31, 132-137.

https://doi.org/10.1016/j.jpag.2017.08.007

[14] Smolinski, S.E., Kreychman, A. and Catanzano, T. (2015) Ovarian Torsion: Multimodality Review of Imaging Characteristics. Journal of Computer Assisted Tomography, 39, 922-924. https://doi.org/10.1097/RCT.0000000000000332 